\title{
Differentiated Thyroid Carcinoma and Late Onset of Lung Distant Metastasis. A Case Report
}

\author{
Alessandro Semprebene ${ }^{1}$, Anna Maria Mangano ${ }^{1}$, Guido Ventroni ${ }^{1}$, Raffaella Barone ${ }^{1}$, \\ Francesca Romana Piro ${ }^{2}$ and Lucio Mango ${ }^{1, *}$ \\ 1 Nuclear Medicine Department, “S. Camillo-Forlanini” General Hospital, 00151 Rome, Italy; \\ a.semprebene@scf.gov.it (A.S.); a.mangano@scf.gov.it (A.M.M.); g.ventroni@scf.gov.it (G.V.); \\ r.barone@scf.gov.it (R.B.) \\ 2 . Pathology Department, "S. Giovanni-Addolorata” General Hospital, 00184 Rome, Italy; \\ frpiro@hsangiovanni.roma.it \\ * Correspondence: 1.mango@scf.gov.it; Tel.: +39-335-845-6518
}

Received: 9 December 2018; Accepted: 31 January 2019; Published: 2 February 2019

\begin{abstract}
Background: Differentiated thyroid carcinoma (DTC), which includes the papillary and follicular variants, is a common neoplasm. DTC has a very high cure rate and is treated surgically, usually followed by ablation of the post-surgical remnant with radioiodine. Case Presentation: The case of a 68-year-old male patient who underwent a minimally invasive complete thyroidectomy on July 4, 2007 for capsulated follicular carcinoma with margins of excision exempted from neoplastic infiltration (AJCC 2002 pT2 PNX PMX) is presented. Discussion: As the patient showed the presence of a pulmonary metastasis after 11 years, the potential implications of DTC follow-up management are here summarized. Conclusions: Follow up must be continued throughout life.
\end{abstract}

Keywords: differentiated thyroid carcinoma; metastasis; 131-Iodine; Thyroglobulin

\section{Introduction}

Differentiated thyroid carcinoma, which includes the papillary and follicular variants, is a common neoplasm whose incidence has increased in recent years, probably due to heightened medical surveillance and more addressability to surgery. In this way, many cancers are diagnosed while under one $\mathrm{cm}[1]$.

Compared to that of other tumors, his prognosis is favorable. However, optimal survival results are achieved only through a coordinated multimodal therapy. Differentiated thyroid carcinoma has a very high cure rate and is treated surgically, usually followed by ablation of the post-surgical remnant with radioiodine [2-5].

Some prognostic factors for thyroid carcinoma have been identified by several authors. These factors include patient characteristics like age at diagnosis and gender, and tumor characteristics, such as histology and stage at diagnosis [6-9].

Some authors also include the possibility of overexpression of microRNAs, which suggests a possible involvement in the differentiation and malignancy $[10,11]$.

The 10-year overall survival rates for papillary and follicular carcinomas are reported in many cases of $93 \%$ and $85 \%$, respectively, with a weak dependence on age or differentiation of the tumor. The risk of persistent or recurrent disease must be reassessed depending on the initial therapy response [12-14]. 


\section{Case Presentation Section}

The patient is a 68-year-old male who underwent complete thyroidectomy on 4 July 2007 following the diagnosis of multinodular goiter with the prevalence of a single nodule with suspicious clinical and echotomographic features (growth progressive and vascular pattern type III).

The histological examination following surgery showed the presence in the right lobe of multiple nodular areas of up to $1.8 \mathrm{~cm}$ in diameter having the histological characteristics of nodular hyperplasia. On the other hand, the presence of a nodular formation with a maximum diameter of $2.8 \mathrm{~cm}$ at expansive growth margins was observed. The histological examination confirmed the presence in the right lobe of multiple nodular areas with the histological characteristics of nodular hyperplasia. In the left lobe, there was a unique nodular formation of gray-brownish color of approximately $2.8 \mathrm{~cm}$, with expansive growth margins and the presence of a pseudo capsule. The final histological finding was: "... capsulated follicular carcinoma (Figure 1) with capsular invasion of the thyroid gland (Figure 2) and margins of exeresis free of neoplastic infiltration. AICC 2002: pT2pNxpMxR0."

In September 2007, after appropriate opotherapy suspension, he underwent a nuclear medicine treatment with an administered radioactive iodine [15] activity of $3.7 \mathrm{GBq}$. At the time of admission, he had a value of serum thyroglobulin (Tg) [16] equal to $3.49 \mathrm{ng} / \mathrm{mL}$ and of Thyrotropin (TSH) equal to $86.7 \mu \mathrm{U} / \mathrm{mL}$. Five days after the iodine administration, a Whole Body (WB) scan was performed to evaluate the distribution of the tracer in the body. The scan only showed an area of radioactive iodine concentration in the antero-cervical area as expression of the presence of post-surgical thyroid remnant.

After eight months (in June 2008) a subsequent whole body scintigraphic re-evaluation, after stimulation with Recombinant human TSH (rh-TSH) [17], was performed. It showed the disappearance of the activity in the antero-cervical area and a physiological distribution of the radiopharmaceutical in the various body districts. The $\mathrm{Tg}$ value after stimulus was of $0.2 \mathrm{ng} / \mathrm{mL}$ and TSH value at the maximum stimulation was of $94 \mu \mathrm{U} / \mathrm{mL}$.

During follow-up, two more WB iodine scan after rh-TSH stimulation were performed (in January 2010 (Figure 3) and in November 2011). Once more the scans demonstrated a physiological distribution of the radiopharmaceutical in the various body districts, areas of pathological radiopharmaceutical uptake and serum $\mathrm{Tg}$ values always lower than $0.2 \mathrm{ng} / \mathrm{mL}$ after an adequate elevation of TSH values.

In the first seven years from thyroidectomy annual echotomographic evaluations of the neck region were added to the scintigraphic assessments, all without significant findings. Additionally, half-yearly dosages of serum $\mathrm{Tg}$ and anti-Tg antibodies [18], with values always lower than $1 \mathrm{ng} / \mathrm{mL}$ and $60(\mathrm{U} / \mathrm{mL})$, respectively, were performed. Further, the periodic dosage of TSH and thyroid hormones has always highlighted adequate therapy with L-thyroxine.

Since July 2016 during the annual follow-up during therapy with L-thyroxine was observed a progressive increase in serum Tg values, up to $6.2 \mathrm{ng} / \mathrm{mL}$, with normal levels of anti-Tg antibodies and the absence of significant findings in the antero-cervical area at ultrasound. In December 2017, a new whole body scintigraphic evaluation with 131I after stimulation with rh-TSH was performed for a more complete evaluation. After $48 \mathrm{~h}$ the radiopharmaceutical administration, a whole-body scan was performed (Figure 4), accompanied by a static acquisition of the neck and thorax and a SPECT/CT(Tomoscintigraphy and Computed Tomography) scan of the thoracic region (Figure 5). 


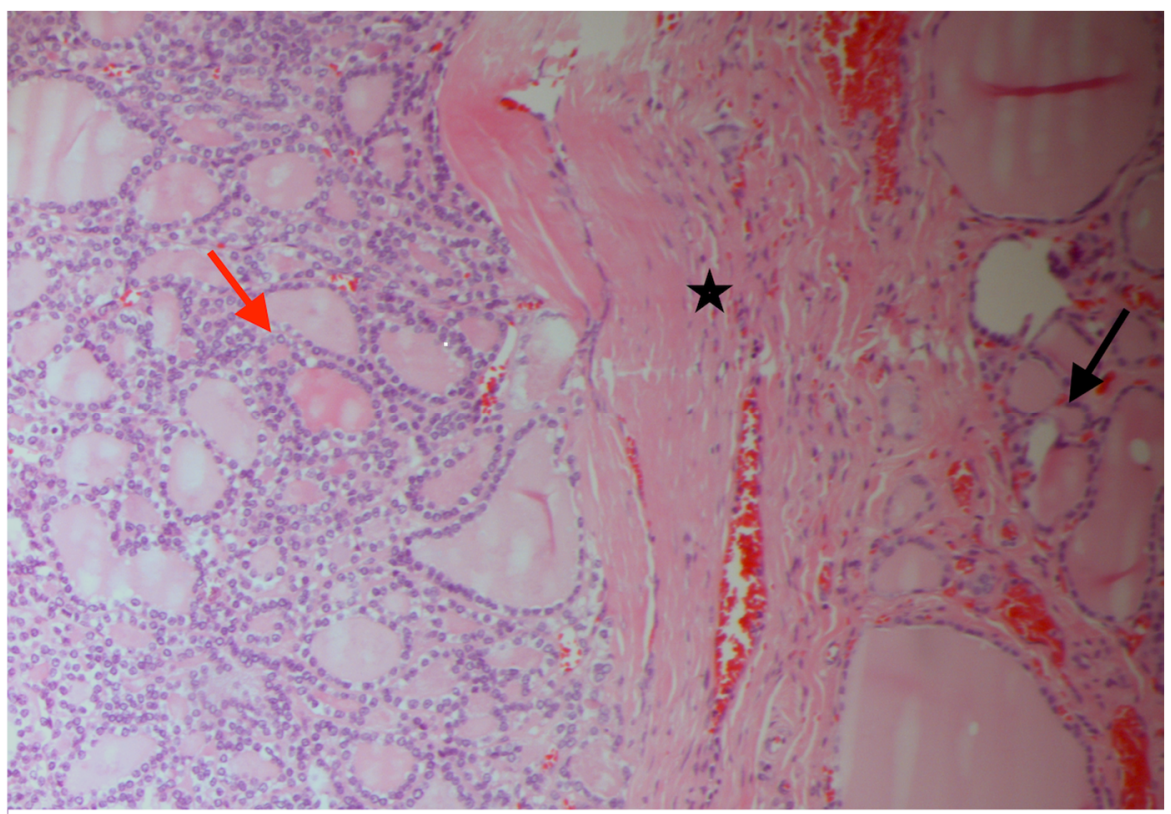

Figure 1. Interfacie between the normal tissue (black arrow) and the tumor (red arrow). The capsule-indicated by the black star-is a thick fibrous band that separates the two tissues.

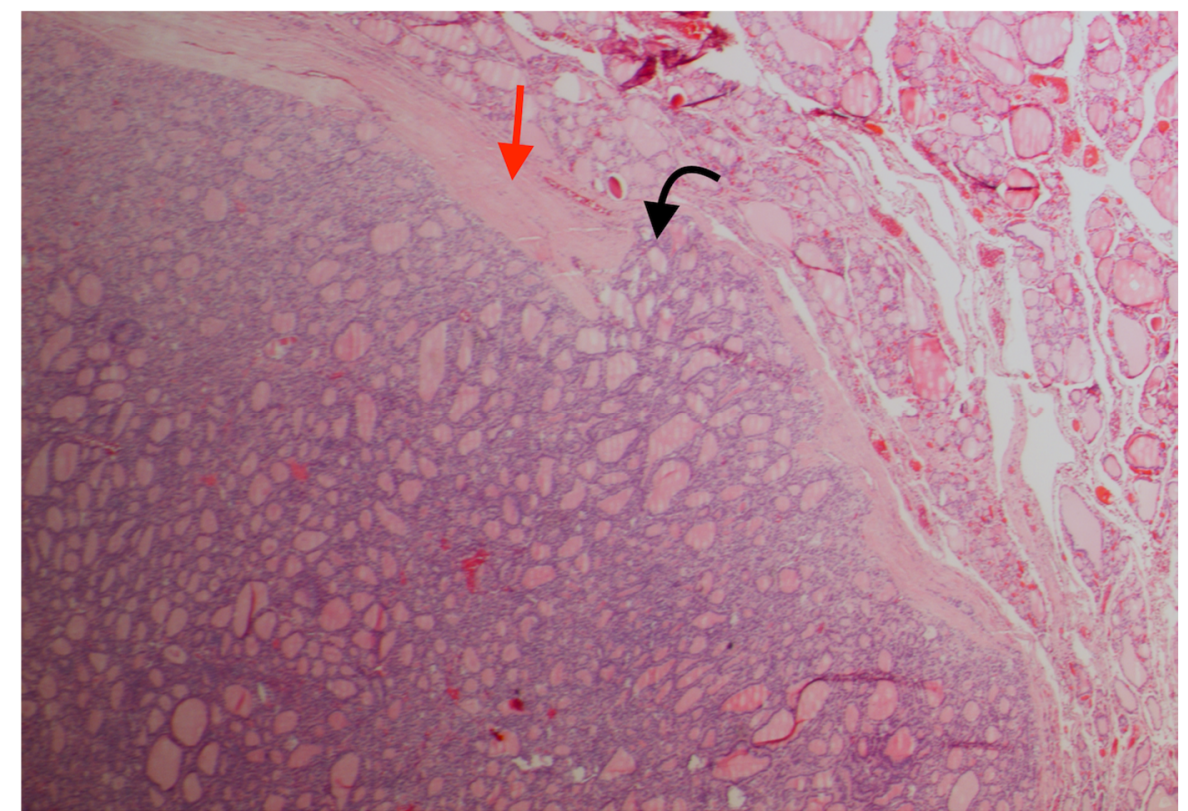

Figure 2. Diagnostic key: the neoplastic tissue (black arrow) protrudes through the capsule (red arrow) and exceeds it, forming a sort of mushroom. 


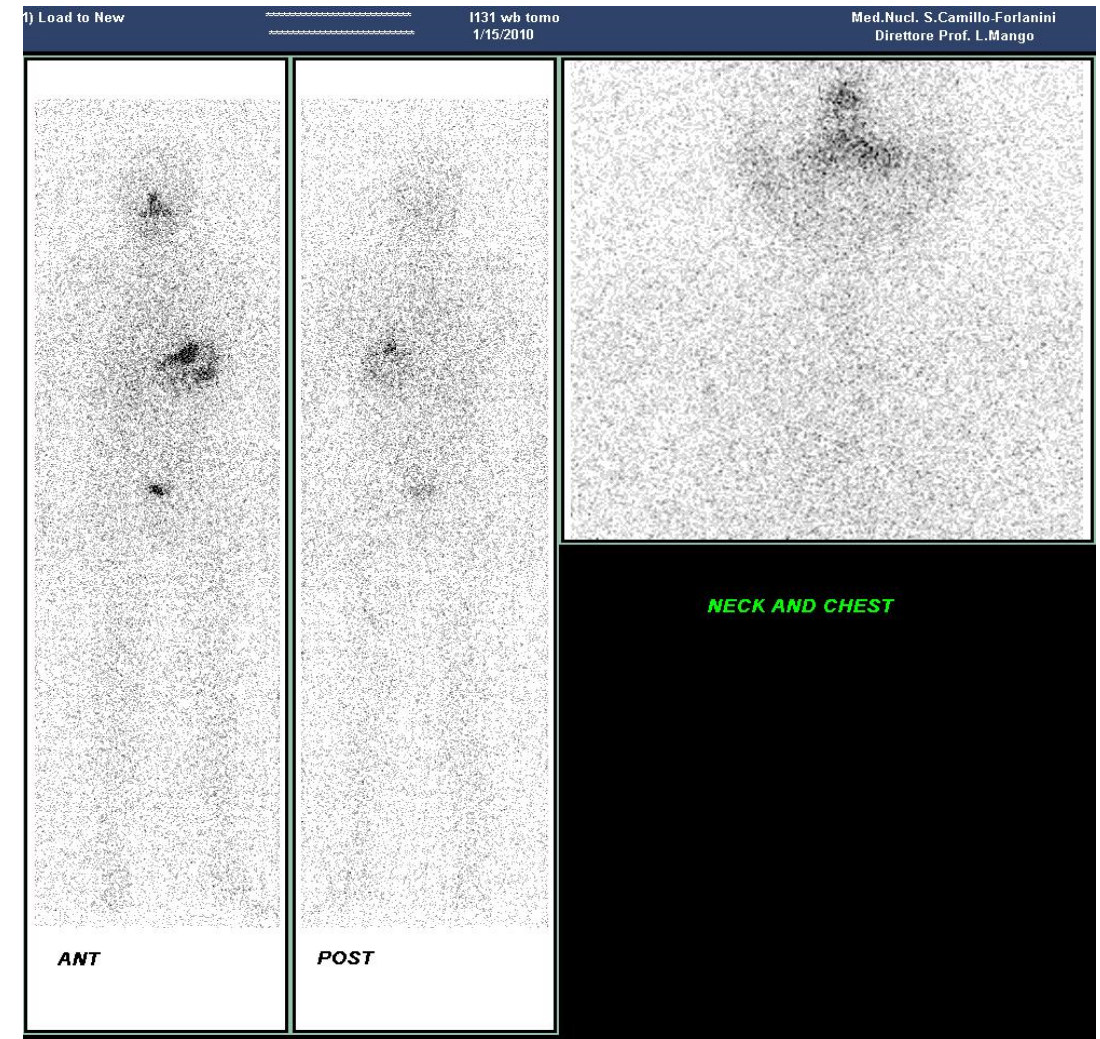

Figure 3. Normal findings on Whole Body iodine scan after Recombinant human TSH (rh-TSH) stimulation (2010).

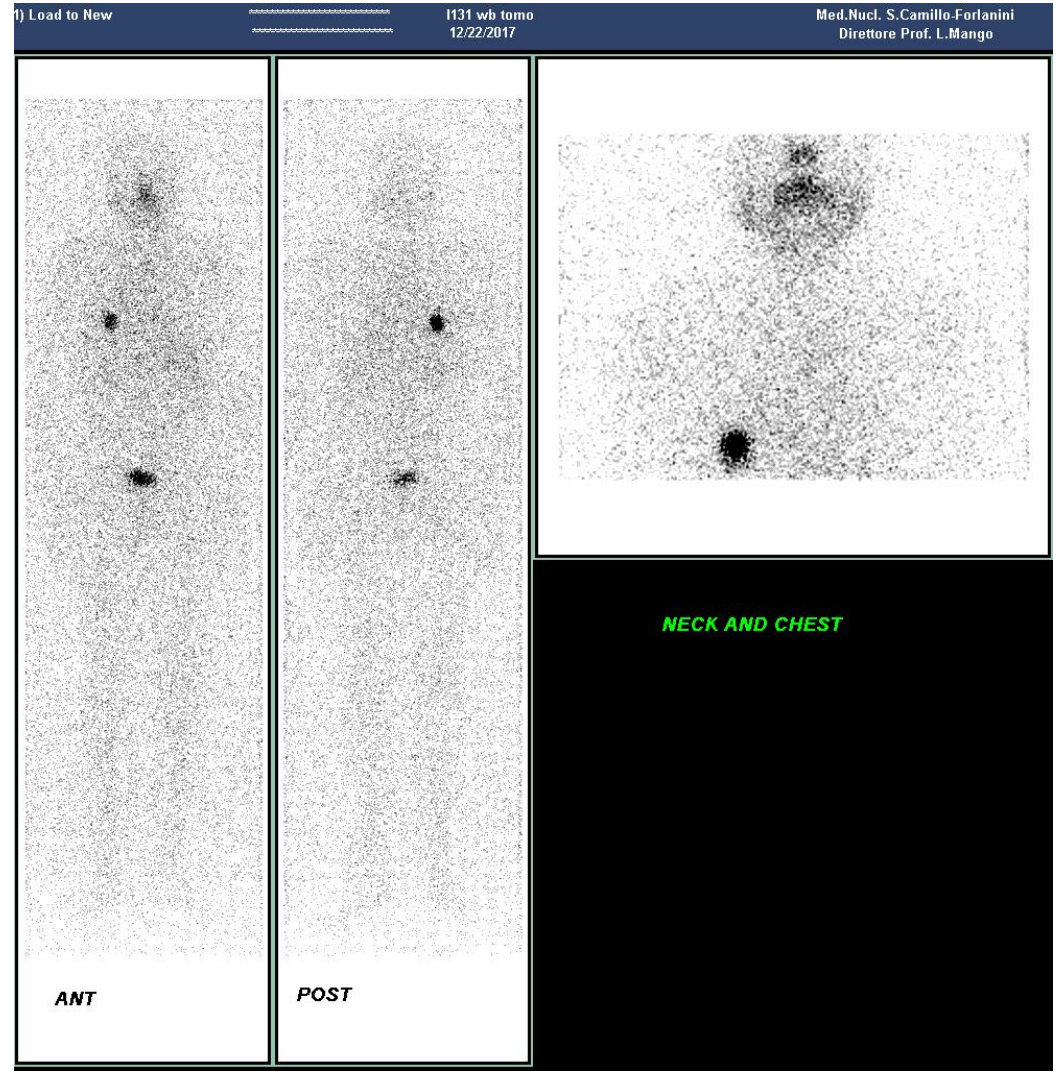

Figure 4. Right lung metastases on WB iodine scan after rh-TSH stimulation (2017). 


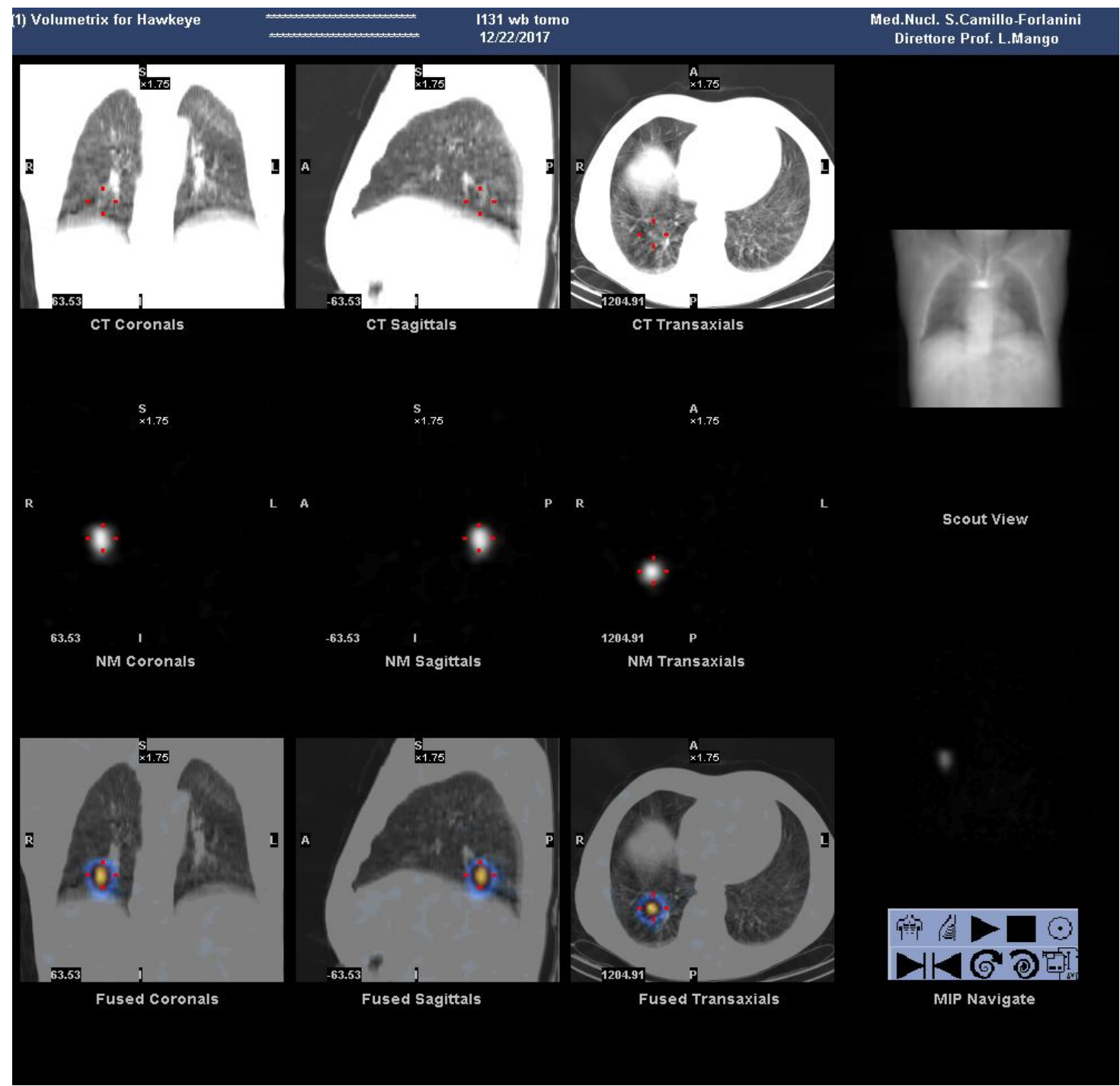

Figure 5. SPECT-CT of the chest taken at the same time of WB, shown in Figure 2 (2017).

These investigations detected an area of focal accumulation of 131I at the postero-basal region of the right lung. On the fourth day the Tg value increased and reached the value of $18.6 \mathrm{ng} / \mathrm{mL}$ with the $\mathrm{TSH}$ value equal to $92.17 \mathrm{microU} / \mathrm{mL}$

For these reasons, in February 2018 the patient underwent a new course of 131I therapy after stimulation with rh-TSH (0.9 mg i.m.); on the second day the serum Tg values reached $10.77 \mathrm{ng} / \mathrm{mL}$ and the TSH value reached $137 \mu \mathrm{U} / \mathrm{mL}$.

The activity of 131I administered was equal to $7.4 \mathrm{GBq}$; seven days after the whole-body investigation and SPECT/CT of the thorax confirmed the presence of a single pathological accumulation of activity in the postero-basal region of the right lung.

The patient is (obviously) still undergoing follow-up and the next check has been scheduled for February 2019

\section{Discussion}

Several prognostic systems are designed in order to identify high-risk patients who need a more aggressive treatment and then reduce morbidity and mortality. Some of them are: The TNM scoring systems (Tumor, Nodes, Metastases), the AGES (Age, Grade, Extent, Size), the MACIS (Metastases, Age, Completeness of resection, Invasion, Size), the AMES (Age, Metastases, Extent, Size), and the EORTC 
(European Organization for Research and Treatment of Cancer). The MACIS scoring system has been recognized by some authors as the most prognostic system, followed by the AGES, the EORTC, the AMES, and the TNM [19].

The quality of data related to the prognosis of a given thyroid neoplasia and its final outcome does not depend only by the biology of the neoplasm or the characteristics of the individual patient, but also on the validity and duration of the treatment and the post-operative follow-up. Especially the latter is linked to the sensitivity of the diagnostic methods used for confirmation of disease recurrence, to demographic factors and to the type of treatments performed. Age at diagnosis is confirmed to be an important element of evaluation $[7,20]$. The adverse effect of age on prognosis gradually increases every ten years of life, especially after the $40-45$ years of age. Older patients are affected by a higher incidence of aggressive histological variants, extensive disease and distant metastases already at diagnosis. Tumors tend to be less differentiated in the elderly, there is a minor iodine-131 uptake compared to younger subjects, and there occurs a greater and more rapid incidence of recurrence of the disease after the initial treatment [21]. BRAF mutation was identified as the most common mutation in DTC after the advent of molecular testing. In the diagnosis or prognosis of DTC, however, its role has not yet been clearly defined; mutational testing can be undertaken for nodules that have atypical or suspicious cytology to help the surgeon decide [22].

Radioiodine remains the primary diagnostic agent to determine the presence of both normal and thyroid pathological tissue after thyroidectomy, and as demonstrated by the presented case, even during follow-up. According to some long-term retrospective studies, the improvement in survival rates and the decrease in recurrence rates after radioiodine ablation have been documented. These studies documented that the treatment with radioiodine was the only and most powerful prognostic indicator for a disease-free interval and a greater survival [19]. Several studies have shown a reduction in recurrence, a reduction in distant metastases, and a lengthening of survival due to the ablative use of 131I; this is better demonstrated in patients with a high risk of recurrence and with the presence or risk of metastasis, because, in this instance, this method reduces the overall mortality [23-25].

In the same way, the postoperative evaluation of the serum $\mathrm{Tg}$ test is recommended. In the case of absence of anti-thyroglobulin antibodies interfering on the assay, and in the presence of TSH stimulation, the existence of reduced $(<1 \mathrm{ng} / \mathrm{mL})$ or undetectable Tg levels is strong evidence of the absence of disease, while a high or measurable serum $\mathrm{Tg}$ indicates the possible presence of metastasis or recurrence of thyroid neoplasia [26-29].

PET diagnostics can also be applied to DTC. Some authors have recently demonstrated that 18F-FDG PET/CT may be of great value in identifying metastases in postoperative DTC patients with elevated $\mathrm{Tg}$ values before $131 \mathrm{I}$ administration, leading to an improved management of disease [30].

\section{Conclusions}

In conclusion, the description of this case is relevant because the recurrence with distant metastases in a DTC patient who achieved excellent response is exceptional.

In fact, despite the low invasion of DTC, the known low frequency of recurrence, of the onset of distant metastases and an expected long survival, the case presented requires that the control must be continued throughout life [31,32]. Additionally, if there is a relapse, that is generally present in the first years of follow-up, it can appear even at a further distance of time.

Acknowledgments: English version of the text edited by Ludovica Mango, graduate interpreter.

Funding: This research received no external funding.

Conflicts of Interest: The authors declare no conflict of interest. 


\section{References}

1. Enache, O.S.; Martin, S.; Ion, O.; Grigore, A.; Bojoga, I.; Parfeni, O.; Sirbu, A.; Barbu, C.; Giulea, C.; Miron, A.; et al. Thyroid cancer prevalence and pathological features in thyroidectomy patients-five years experience. In Proceedings of the 20th European Congress of Endocrinology, Barcelona, Spain, 19-22 May 2018; p. 1161.

2. Mazzaferri, E.L.; Jhiang, S.M. Long-term impact of initial surgical and medical therapy on papillary and follicular thyroid cancer. Am. J. Med. 1994, 97, 418-428. [CrossRef]

3. Ronga, G.; Filesi, M.; Ferranti, E.; Mango, L.; Barone, R.; Procaccini, E.; Ventroni, G.; Signore, A.; Baschieri, I. Histology and survival in 1085 patients treated with 131I for thyroid cancer. Q. J. Nucl. Med. 1996, 40, 8.

4. Pacini, F.; Schlumberger, M.; Harmer, C.; Berg, G.G.; Cohen, O.; Duntas, L.; Jamar, F.; Jarzab, B.; Limbert, E.; Lind, P.; et al. Post-surgical use of radioiodine (131I) in patients with papillary and follicular thyroid cancer and the issue of remnant ablation: A consensus report. Eur. J. Endocrinol. 2005, 153, 651-659. [CrossRef] [PubMed]

5. Andresen, N.S.; Buatti, J.M.; Tewfik, H.H.; Pagedar, N.A.; Anderson, C.M.; Watkins, J.M. Radioiodine ablation following thyroidectomy for differentiated thyroid cancer: Literature review of utility, dose, and toxicity. Eur. Thyroid. J. 2017, 6, 187-196. [CrossRef]

6. Thoresen, S.O.; Akslen, L.A.; Glattre, E.; Haldorsen, T.; Lund, E.V.; Schoultz, M. Survival and prognostic factors in differentiated thyroid carcinoma: A multivariate analysis of 1,055 cases. Br. J. Surg. 1989, 59, 231-235.

7. Filesi, M.; Signore, A.; Mango, L.; Barbarossa, C.; Procaccini, E.; Righi, V.A.; Ronga, G.; Baschieri, I. 131I therapy and survival in young patients with differentiated thyroid carcinoma. Q. J. Nucl. Med. 1996, 40, 90.

8. Filesi, M.; Mango, L.; Salerno, G.; Barbarossa, C.; Barone, R.; Ciancamerla, M.; Paserio, E.; Ventroni, G.; Ronga, G. Diagnostic value for metastases of first 131I WBS post thyroidectomy for differentiated cancer. Q. J. Nucl. Med. 1996, 40, 74.

9. Tran, B.M.; Roshan, D.J.; Abraham, E.; Wang, L.Y.; Garibotto, N.; Wykes, J.; Campbell, P.; Ebrahimi, A. The Prognostic Impact of Tumor Size in Papillary Thyroid Carcinoma is Modified by Age. Thyroid 2018, 28. [CrossRef]

10. Calabrese, G.; Dolcimascolo, A.; Torrisi, F.; Zappalà, A.; Gulino, R.; Parenti, R. MiR-19a Overexpression in FTC-133 Cell Line Induces a More De-Differentiated and Aggressive Phenotype. Int. J. Mol. Sci. 2018, 19, 3944. [CrossRef]

11. Hu, J.; Li, C.; Liu, C.; Zhao, S.; Wang, Y.; Fu, Z. Expressions of miRNAs in papillary thyroid carcinoma and their associations with the clinical characteristics of PTC. Cancer Biomark 2017, Pre-press, 1-8. [CrossRef]

12. Hundahl, S.A.; Fleming, I.D.; Fremgen, A.M.; Menck, H.R. A National Cancer Data Base report on 53,856 cases of thyroid carcinoma treated in the U.S., 1985-1995. Cancer. 1998, 83, 2638-2648. [CrossRef]

13. Brennan, M.D.; Bergstralh, E.J.; van Heerden, J.A.; McConahey, W.M. Follicular thyroid cancer treated at the Mayo Clinic, 1946 through 1970: Initial manifestation, pathologic findings, therapy, and outcome. Mayo. Clin. Proc. 1991, 66, 11-22. [CrossRef]

14. Jonathan, M.; Steward, D.L. Surgical Management of Low-Risk Papillary Thyroid Cancer. In Management of Thyroid Nodules and Differentiated Thyroid Cancer; Springer: Cham, Switzerland, 2017; pp. 231-240.

15. Chan, T.W.; Hurley, J.R.; Fahey, T.J. Postoperative Radioactive Iodine for Differentiated Thyroid Cancer: A Historical Perspective. Clin. Oncol. 2017, 2, 1230.

16. Baudin, E.D.C.C.; Cao, C.D.; Cailleux, A.F.; Leboulleux, S.; Travagli, J.P.; Schlumberger, M. Positive predictive value of serum thyroglobulin levels, measured during the first year of follow-up after thyroid hormone withdrawal, in thyroid cancer patients. J. Clin. Endocrinol. MeTab. 2003, 88, 1107-1111. [CrossRef] [PubMed]

17. Alzahrani, A.S.; AlShaikh, O.; Tuli, M.; Al-Sugair, A.; Alamawi, R.; Al-Rasheed, M.M. Diagnostic value of recombinant human thyrotropin-stimulated 123 I whole-body scintigraphy in the follow-up of patients with differentiated thyroid cancer. Clini. Nucl. Med. 2012, 37, 229-234. [CrossRef] [PubMed]

18. Spencer, C.A.; Takeuchi, M.; Kazarosyan, M.; Wang, C.C.; Guttler, R.B.; Singer, P.A.; Fatemi, S.; LoPresti, J.S.; Nicoloff, J.T. Serum thyroglobulin autoantibodies: Prevalence, influence on serum thyroglobulin measurement, and prognostic significance in patients with differentiated thyroid carcinoma. J. Clin. Endocrinol. Metab. 1998, 83, 1121-1127. [CrossRef] [PubMed]

19. Teo, K.W.; Yuan, N.K.; Tan, W.B.; Parameswaran, R. Comparison of prognostic scoring systems in follicular thyroid cancer. Ann. R Coll. Surg. Engl. 2017, 99, 479-484. [CrossRef] [PubMed] 
20. Ito, Y.; Miyauchi, A.; Kihara, M.; Fukushima, M.; Higashiyama, T.; Miya, A. Overall Survival of Papillary Thyroid Carcinoma Patients: A Single-Institution Long-Term Follow-Up of 5897 Patients. World J. Surg. 2018, 42, 615-622. [CrossRef] [PubMed]

21. Hay, I.D.; Thompson, G.B.; Grant, C.S.; Bergstralh, E.J.; Dvorak, C.E.; Gorman, C.A.; Maurer, M.S.; McIver, B.; Mullan, B.P.; Oberg, A.L.; et al. Papillary thyroid carcinoma managed at the Mayo Clinic during six decades (1940-1999): Temporal trends in initial therapy and long-term outcome in 2444 consecutively treated patients. World J. Surg. 2002, 26, 879-885. [CrossRef] [PubMed]

22. Soares, P.; Celestino, R.; Melo, M.; Fonseca, E.; Sobrinho-Simões, M. Prognostic biomarkers in thyroid cancer. Virchows. Arch. 2014, 464, 333.

23. Cailleux, A.F.; Baudin, E.; Travagli, J.P.; Ricard, M.; Schlumberger, M. Is diagnostic iodine-131 scanning useful after total thyroid ablation for differentiated thyroid cancer? J. Clin. Endocrinol. Metab. 2000, 85, 175-178. [CrossRef] [PubMed]

24. Samaan, N.A.; Schultz, P.N.; Hickey, R.C.; Goepfert, H.; Haynie, T.P.; Johnston, D.A.; Ordonez, N.G. The results of various modalities of treatment of well differentiated thyroid carcinomas: A retrospective review of 1599 patients. J Clin Endocrinol Metab. 1992, 75, 714-720. [PubMed]

25. Pacini, F.; Basolo, F.; Bellantone, R.; Boni, G.; Cannizzaro, M.A.; De Palma, M.; Durante, C.; Elisei, R.; Fadda, G.; Frasoldati, A.; et al. Italian consensus on diagnosis and treatment of differentiated thyroid cancer: Joint statements of six Italian societies. J. Endocrinol. Invest. 2018, 41, 849-876. [CrossRef] [PubMed]

26. Mazzaferri, E.L. Thyroid remnant 131I ablation for papillary and follicular thyroid carcinoma. Thyroid 1997, 7, 265-271. [CrossRef] [PubMed]

27. Burch, H.B. Papillary Thyroid Cancer. In Thyroid Cancer; Humana Press: Totowa, NJ, USA, 2000; pp. $229-237$.

28. Webb, R.C.; Howard, R.S.; Stojadinovic, A.; Gaitonde, D.Y.; Wallace, M.K.; Ahmed, J.; Burch, H.B. The utility of serum thyroglobulin measurement at the time of remnant ablation for predicting disease-free status in patients with differentiated thyroid cancer: A meta-analysis involving 3947 patients. J. Clin Endocrinol Metab. 2012, 97, 2754-2763. [CrossRef] [PubMed]

29. Yang, X.; Liang, J.; Li, T.; Zhao, T.; Lin, Y. Preablative stimulated thyroglobulin correlates to new therapy response system in differentiated thyroid cancer. J. Clin Endocrinol Metab. 2016, 101, 1307-1313. [CrossRef] [PubMed]

30. Liu, M.; Cheng, L.; Jin, Y.; Ruan, M.; Sheng, S.; Chen, L. Predicting 131 I-avidity of metastases from differentiated thyroid cancer using 18 F-FDG PET/CT in postoperative patients with elevated thyroglobulin. Sci. Rep. 2018, 8, 4352. [CrossRef] [PubMed]

31. Linee Guida SIE-AIMN-AIFM per il Trattamento e Follow-up del Carcinoma Differenziato della Tiroide. Available online: https:/ / www.aimn.it/pubblicazioni/LG/LG_ca_tiroide.pdf (accessed on 1 February 2019).

32. HaugenBryan, R.; AlexanderErik, K.; BibleKeith, C.; DohertyGerard, M.; MandelSusan, J.; NikiforovYuri, E.; Pacini, F.; Randolph, G.W.; Sawka, A.M.; Schlumberger, M.; et al. 2015 American Thyroid Association management guidelines for adult patients with thyroid nodules and differentiated thyroid cancer: The American Thyroid Association guidelines task force on thyroid nodules and differentiated thyroid cancer. Thyroid. 2016, 26, 1-133. [CrossRef] [PubMed]

(C) 2019 by the authors. Licensee MDPI, Basel, Switzerland. This article is an open access article distributed under the terms and conditions of the Creative Commons Attribution (CC BY) license (http://creativecommons.org/licenses/by/4.0/). 